\title{
OPEN The complete chloroplast genome of Gleditsia sinensis and Gleditsia japonica: genome organization, comparative analysis, and development of taxon specific DNA mini-barcodes
}

\author{
Wei Tan ${ }^{1,2}$, Han Gao ${ }^{1,2}$, Weiling Jiang ${ }^{1}$, Huanyu Zhang ${ }^{1}$, Xiaolei Yu ${ }^{1}$, Erwei Liu ${ }^{1 \bowtie} \&$ \\ Xiaoxuan $\operatorname{Tian}^{1} \bowtie$
}

Chloroplast genomes have been widely considered an informative and valuable resource for molecular marker development and phylogenetic reconstruction in plant species. This study evaluated the complete chloroplast genomes of the traditional Chinese medicine Gleditsia sinensis and G. japonica, an adulterant of the former. The complete chloroplast genomes of $G$. sinensis and $G$. japonica were found to be of sizes $163,175 \mathrm{bp}$ and $162,391 \mathrm{bp}$, respectively. A total of 111 genes were identified in each chloroplast genome, including 77 coding sequences, 30 tRNA, and 4 rRNA genes. Comparative analysis demonstrated that the chloroplast genomes of these two species were highly conserved in genome size, GC contents, and gene organization. Additionally, nucleotide diversity analysis of the two chloroplast genomes revealed that the two short regions of $y c f 1 b$ were highly diverse, and could be treated as mini-barcode candidate regions. The mini-barcode of primers ZJ818F-1038R was proven to precisely discriminate between these two species and reflect their biomass ratio accurately. Overall, the findings of our study will shed light on the genetic evolution and guide species identification of $G$. sinensis and $G$. japonica.

Gleditsia (honey locust) is a genus comprising 13 species of the Caesalpinioideae subfamily and Fabaceae family ${ }^{1}$. The honey locust is native to North America and Asia, and a majority of the species diversity is found in eastern $\mathrm{Asia}^{2}$. Previous investigation on plants of the Gleditsia genus showed a variety of bioactivities, including antitumor, anti-inflammatory, anti-hyperlipidemic, anti-allergic, and analgesic ${ }^{3}$. Therefore, plants of the Gleditsia species have been widely used for centuries in local and traditional medicine ${ }^{1}$. For example, G. japonica has long been known to be a diuretic and an expectorant ${ }^{4}$, and the medicinal value of $G$. sinensis is documented in various editions of the Pharmacopoeia of the People's Republic of China, from 1965 to 2015,6. Thorns of the honey locust, known as 'Zao Jiao Ci', are used in traditional oriental medicine as an efficacious therapeutic agent for the treatment of carbuncle, cancers, skin diseases, and suppuration ${ }^{7,8}$. Some components of G. sinensis also constitute some patent medicines, like the Gleditsia pill and Wang Bi capsules.

Angiosperm chloroplast genomes are key organelles for photosynthesis and carbon fixation ${ }^{9}$. The chloroplast genomes are valuable resources for molecular identification and phylogenetic studies because of a series of superiorities including the compact size, less recombination, maternal inheritance, self-replication, high copy number, and moderate substitution rates ${ }^{10-13}$. Comparative analysis of the chloroplast genomes of closely related species is crucial for grasping various aspects of genome evolution, focused on the structural variations and gene

\footnotetext{
${ }^{1}$ State Key Laboratory of Component-based Chinese Medicine, Tianjin University of Traditional Chinese Medicine, Poyang Lake Road 10, Tianjin 301617, China. ${ }^{2}$ These authors contributed equally: Wei Tan and Han Gao. ${ }^{\square}$ email: liuwei628@hotmail.com; tian_xiaoxuan@tjutcm.edu.cn
} 
losses ${ }^{14}$. However, only one chloroplast genome of the genus Gleditsia has been reported so far ${ }^{15}$, which highly limits our understanding of the evolution and phylogeny of Gleditsia.

Due to their similar morphologic characteristics, unintentional adulteration of G. sinensis and G. japonica frequently occurs in China ${ }^{16}$. The current methods for distinguishing between the two include chemical ${ }^{17}$, morphological, and microscopic techniques ${ }^{16}$. However, precise discrimination of processed material of the species is often challenging ${ }^{18}$. DNA barcoding is a molecular marker technology that can accurately and rapidly identify different species and does not require any specialized training or evaluation of obvious morphological characteristics $^{19,20}$. Previous studies have used the $n d h F$ and $r p l 16$ gene sequences ${ }^{21}$ of 11 species of the Gleditsia genus for phylogenetic and biogeographic analysis in Gleditsia. Besides, the trnL-trnF intergenic spacer and the $\operatorname{trnL}$ intron $^{22}$ have also been used to distinguish between five Gleditsia species. Further, some researchers sequenced $p s b A$-trn $H^{23}$ and $m a t K^{24}$ to identify G. sinensis. However, the fruits and thorns of G. sinensis, which are used in traditional medicine and several Chinese patent medicines usually undergo varying degrees of DNA degradation during harvesting, storage, and processing. Notably, the amplification of the full-length barcode in the degraded samples is challenging ${ }^{25}$. At the same time, the common markers (438-2098 bp) could introduce serious bias in biomass estimation when applied for metabarcoding analysis of degraded DNA mixtures ${ }^{26}$. To mitigate the problem of DNA degradation and quantitative inaccuracy, numerous studies have indicated that mini-barcodes (generally $\leq 200 \mathrm{bp}$ ) can be used instead of the traditional full-length barcodes, as they distinguish between limited species ${ }^{27-29}$. Therefore, our aim is to develop a mini-barcode that can be used for the quantitative identification of $G$. sinensis and its counterfeit G. japonica. For seed plants, such barcodes are identified by screening the chloroplast genome, owing to its advantages stated above $\mathrm{e}^{20,30}$.

In this study, we sequenced the complete chloroplast genome of G. sinensis and G. japonica, which have been less studied in previous researches. The specific aims of the present study were to: (1) obtain the complete chloroplast genomes of G. sinensis and G. japonica; (2) carry out a comparative analysis of the chloroplast genomes of these two species; (3) evaluate the monophyletic and systematic position of Gleditsia by reconstructing phylogenetic relationships of the 152 species of the Fabaceae family; (4) detect the suitable mini-barcode region for species identification of these two species; (5) validate the quantitative capacity of mini-barcode primers by meta-barcoding. Our results will provide valuable data for accurate species-level discrimination between $G$. sinensis and G. japonica and help preserving the quality of $G$. sinensis as an important Chinese medicine.

\section{Results}

Complete chloroplast genome features and organization of $G$. sinensis and $G$. japonica. As shown in Fig. 1, the two Gleditsia species displayed similar quadripartite structures, including a pair of inverted repeats in the IR regions (IR), one large single-copy (LSC) region, and one small single-copy (SSC) region. The chloroplast genome sizes of G. sinensis and G. japonica were 163,175 bp and 162,391 bp, respectively. Each chloroplast genome encoded 111 unique genes, including 77 coding sequences, 30 tRNA and 4 rRNA genes. The $\mathrm{G}+\mathrm{C}$ content of the $G$. sinensis chloroplast genome was $35.6 \%$, which demonstrated congruence with that of $G$. japonica (35.5\%) (Table 1). Furthermore, infA and rpl22 genes were lost in each species because of transfer to the nucleus ${ }^{31,32}$ (Table 2). The rps12 gene was spliced into two transcripts, with exon 1 in the LSC region and exons 2 and 3 in the IR region, which is consistent with that in the previous studies ${ }^{33,34} .15$ genes ( $r p l 16, r p l 2, r p s 16$, rpoC1, trnA-UGC, trnG-UCC, trnI-GAU, trnK-UUU, trnV-UAC trnL-UAA, ndhA, ndhB, petB, petD, and atpF) contained one intron, and two genes, i.e., clpP, ycf3 harbored two introns (Table 2).

Repeated sequence analysis. Simple sequence repeats (SSR) that are highly polymorphic at the intraspecific level could be treated as molecular markers in population genetics and evolutionary studies ${ }^{30,35}$. Besides, mononucleotide SSR markers derived from chloroplast genomes form an excellent basis for studying the female lineage of polyploid species, because of their uniparental inheritance and non-recombination during sexual reproduction ${ }^{36,37}$. In this study, a total of 93 microsatellites were identified in the chloroplast genome of G. sinensis, including 87 mononucleotide and 6 dinucleotide SSR. Meanwhile, a total of 100 SSR were detected in the whole chloroplast genome of G. japonica, comprising 96 mononucleotide, 2 trinucleotide, and 2 tetranucleotide SSR (Fig. 2A). The most abundant microsatellites were mononucleotide repeats (183), accounting for about $96.45 \%$ of the total SSR (193). Among all mononucleotides, about $99.45 \%$ were A/T (182), whereas C/G (1) only accounted for $0.55 \%$ (Fig. $2 \mathrm{~B}$ ). This result is congruent with the previous observation that chloroplast genome SSR are generally composed of $\mathrm{A} / \mathrm{T}$, and rarely $\mathrm{C} / \mathrm{G}^{38}$. The second abundant SSR were dinucleotide repeats (8), followed by trinucleotide repeats (2), while tetranucleotide, hexanucleotide and pentanucleotide repeats were not found. Our findings suggest that mononucleotide repeats may contribute to more genetic variations than other SSR, which is consistent with previous study findings ${ }^{35}$.

According to a previous report, the contribution of longer repeat sequences to genome rearrangement and recombination is more significant than that of shorter $\mathrm{SSR}^{39}$. In this study, dispersed repeat segments in the two Gleditsia species were analyzed by REPuter. The results revealed four types of repeated sequences (forward, reverse, palindromic, and complementary) in G. sinensis, but no complementary repeats were detected in G. japonica. Figure $2 \mathrm{C}$ exhibits that most of these repeats were forward and palindromic, with a length range of $30-45$ bps in the two Gleditsia species. Tandem repeats in both species were 120, and the majority of these repeats were between 0 and $30 \mathrm{bp}$ in length (Fig. 2D). In general, the repeats identified in this study will provide valuable information for the study of population relationships in the Gleditsia species.

Analysis of codon preference. As codon usage plays a vital role in shaping chloroplast genome evolution ${ }^{40}$, the relative synonymous codon usage frequency (RSCU) between G. sinensis and G. japonica was calculated using the protein-coding sequences in the chloroplast genomes. The protein sequences contained 26,239 and 


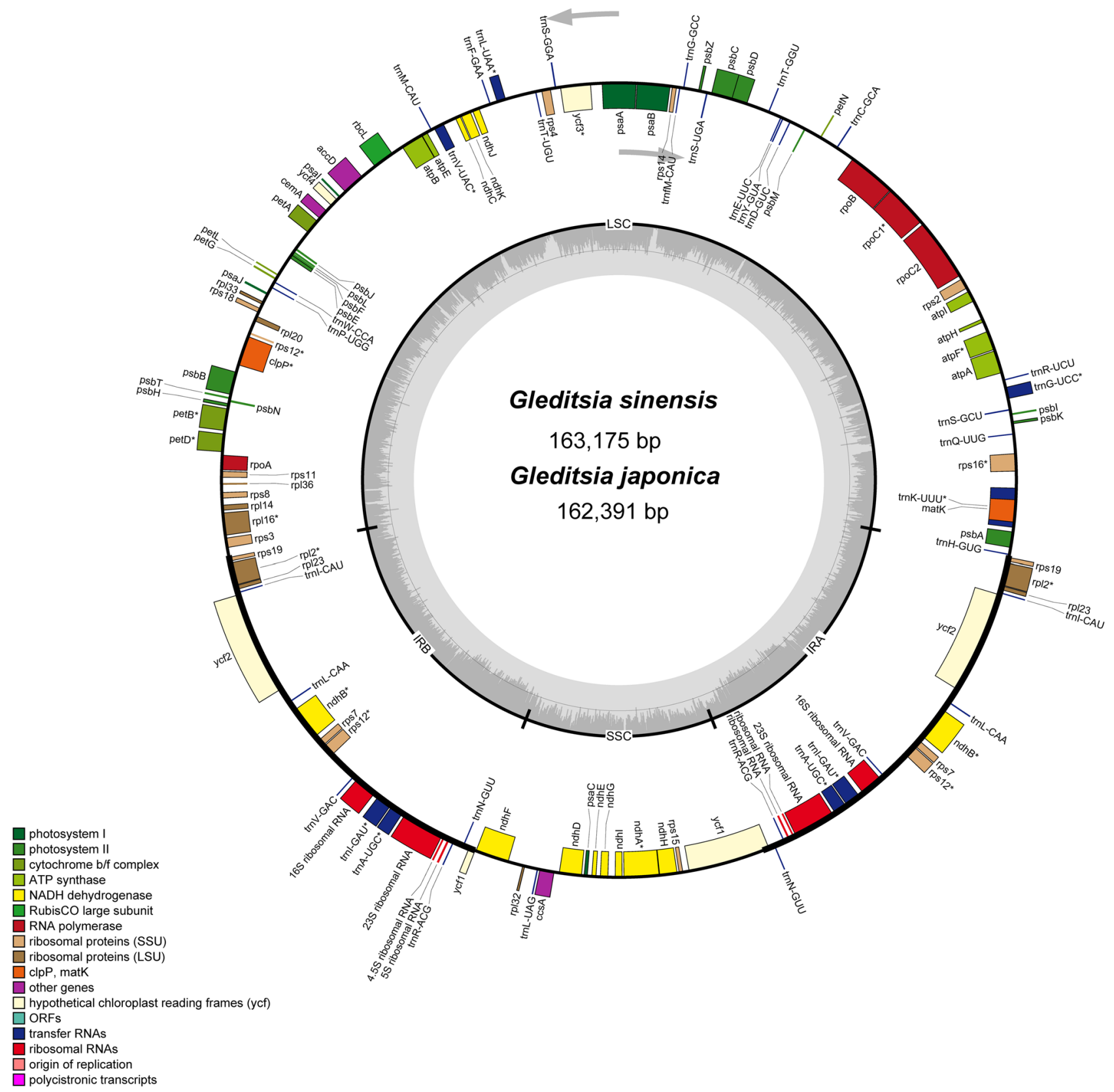

Figure 1. Gene map of the complete chloroplast genomes of the two Gleditsia species. Genes on the inside of the circle are transcribed clockwise, whereas those outside are transcribed counter-clockwise. The dark gray and light gray shading within the inner circle correspond to the percentages of $\mathrm{G}+\mathrm{C}$ and $\mathrm{A}+\mathrm{T}$ contents, respectively.

26,249 codons, respectively, including stop codons. As shown in Fig. 3 and Supplementary Tables S1-S2, leucine was encoded by the highest number (average $=10.56 \%$ and $10.45 \%$ ) of codons, while cysteine (average $=1.193 \%$ and $1.192 \%$ ) was the least encoded in G. sinensis and G. japonica, respectively. In addition, most of the amino acids showed codon bias except methionine (AUG) and tryptophan (UGG) (RSCU =1), which indicated no codon preferences. Similar to the chloroplast genomes of other higher plant ${ }^{40,41}$, nearly all codons of the two species with high RSCU values (RSCU > 1.3) showed a high A/U preference in the third codon. This codon usage pattern may be driven by a composition bias for high proportions of $\mathrm{A} / \mathrm{T}^{41}$. Meanwhile, we found that the chloroplast genome codon usage of these two species was very similar (Fig. 3). In general, the present results revealed the relative conservation of the chloroplast genomes of G. sinensis and G. japonica.

RNA editing site prediction. RNA editing can participate in the post-transcriptional regulation of chloroplast genomes by nucleotide insertion, deletion, or substitution, which provides an effective way of creating transcriptional and translational diversity ${ }^{42,43}$. A total of 52 and 53 RNA editing sites were predicted in 18 chloroplast 


\begin{tabular}{|l|l|l|}
\hline Genome features & Gleditsia sinensis & Gleditsia japonica \\
\hline Total reads (bp) & $29,589,646$ & $28,279,048$ \\
\hline Size (bp) & 163,175 & 162,391 \\
\hline LSC (bp) & 91,540 & 91,449 \\
\hline SSC (bp) & 19,249 & 19,449 \\
\hline IR (bp) & 26,193 & 25,866 \\
\hline Number of genes & 111 & 111 \\
\hline Protein-coding genes & 77 & 77 \\
\hline tRNA genes & 30 & 30 \\
\hline rRNA genes & 4 & 4 \\
\hline Total G+C content (\%) & 35.6 & 35.5 \\
\hline
\end{tabular}

Table 1. Comparison of the chloroplast genome organization of the two Gleditsia species.

\begin{tabular}{|c|c|c|}
\hline Gene category & Gene groups & Names of genes \\
\hline \multirow[b]{5}{*}{ Self-replicating } & Large subunit of ribosome (LSU) & rpl14, rpl16a ${ }^{a}, r p l 2^{a}$ (2), rpl20, rpl23(2), rpl32, rpl33, rpl36 \\
\hline & Small subunit of ribosome (SSU) & $\begin{array}{l}\begin{array}{l}r p s 11, r p s 12^{c}(2), r p s 14, r p s 15, r p s 16^{a}, r p s 18, r p s 19(2), r p s 2, r p s 3, r p s 4, r p s 7(2), \\
r p s 8\end{array}\end{array}$ \\
\hline & DNA dependent RNA polymerase & rpoA, rpoB, rpoC1 ${ }^{a}, r p o C 2$ \\
\hline & rRNA genes & $r r n 16(2), r r n 23(2), r r n 4.5(2), r r n 5(2)$ \\
\hline & tRNA genes & 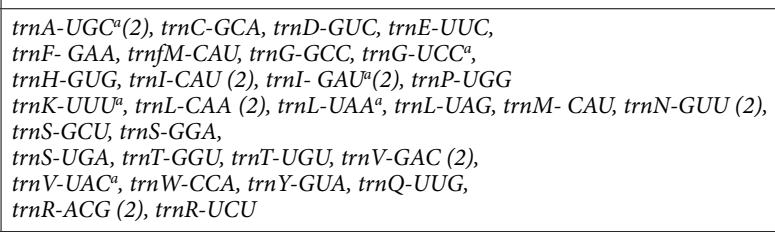 \\
\hline \multirow{6}{*}{ Photosynthesis } & Photosystem I & $p s a A, p s a B, p s a C, p s a I, p s a J$ \\
\hline & Photosystem II & $\begin{array}{l}\text { psbA, psbB, psbC, psbD, psbE, psbF, psbH, psbI, } \\
p s b J, p s b K, p s b L, p s b M, p s b N, p s b T, p s b Z\end{array}$ \\
\hline & NADH dehydrogenase & $\begin{array}{l}\text { ndh } A^{a}, n d h B^{a}(2), n d h C, n d h D, n d h E, n d h F \\
n d h G, n d h H, n d h I, n d h J, n d h K\end{array}$ \\
\hline & Cytochrome b/f complex & petA, pet $B^{a}$, pet $D^{a}$, pet $G$, pet $L$, pet $N$ \\
\hline & Subunits of ATP synthase & atpA, atpB, atpE, atpF $F^{a}$ atpH, atpI \\
\hline & Large subunit of Rubisco & $r b c L$ \\
\hline \multirow{5}{*}{ Other genes } & Protease & $c l p P^{b}$ \\
\hline & Maturase & matK \\
\hline & Envelop membrane protein & сеmA \\
\hline & Subunit of acetyl-CoA & $a c c D$ \\
\hline & C-type cytochrome synthesis gene & $\operatorname{ccs} A$ \\
\hline Unknown function & Proteins of unknown function & $y c f 1$ (2), $y c f 2(2), y c f 3^{b}, y c f 4$ \\
\hline
\end{tabular}

Table 2. Gene contents in the chloroplast genomes of the two Gleditsia species. ${ }^{\text {a }}$ genes containing a single intron. ${ }^{b}$ genes containing two introns. ${ }^{c}$ genes divided into two independent transcription units.

genes of G. sinensis and G. japonica, respectively (Supplementary Tables S3-S4). Among these sites, the highest frequency of amino acid conversion involved serine $(S)$ to leucine $(\mathrm{L})$, which concurs with previous investigations in the chloroplast genomes of higher plant ${ }^{44}$. As previously reported, the number of shared editing sites increases in closely related taxa ${ }^{45}$. In this study, we found that G. sinensis shared editing sites with G. japonica, indicating that RNA editing was evolutionary conserved.

Comparison of the chloroplast genome structures of the two Gleditsia species. Multiple sequence alignment of the chloroplast genomes of the two Gleditsia species was performed by mVISTA, using the annotated chloroplast genome sequence of G. japonica as reference. The result (Fig. 4) showed that the genomes of the two species are highly conserved, with some degree of divergence. Comparative analysis by MAUVE showed that the chloroplast genome structures of the two Gleditsia species were identical (Supplementary Fig. S1). 
A

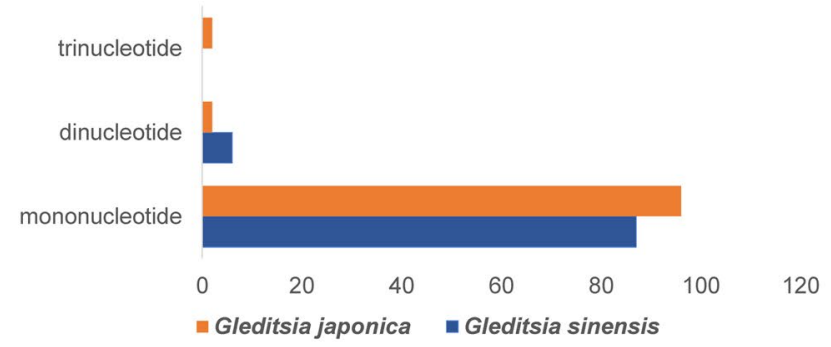

C

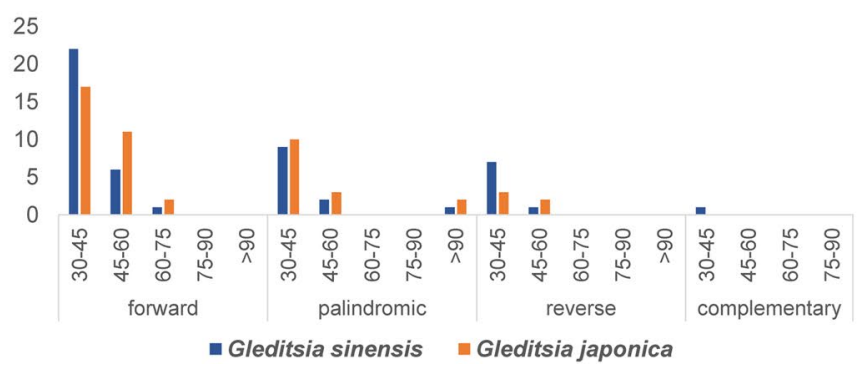

B

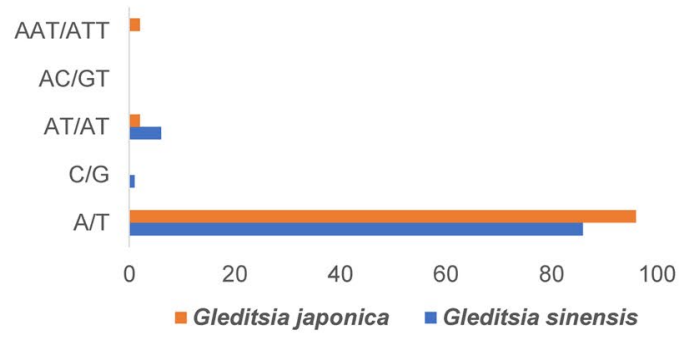

120

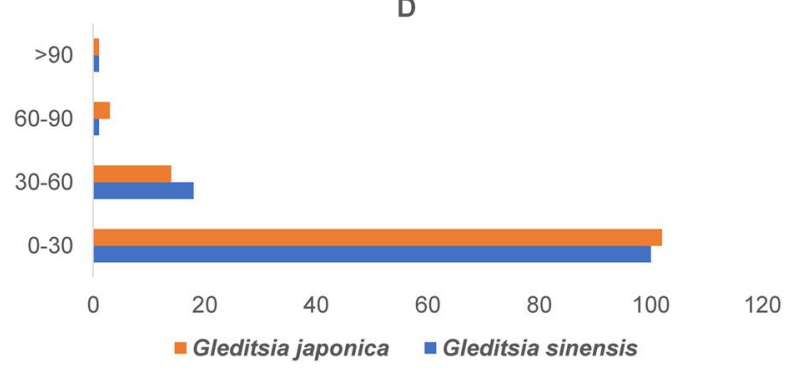

Figure 2. Analysis of repeated sequences in the two Gleditsia species. (A) The numbers of different SSR types, including mononucleotide, dinucleotide, and trinucleotide; (B) Number of different SSR repeat units. (C) Frequency of repeat sequences in the two chloroplast genomes as determined by REPuter; (D) Frequency of tandem repeat sequences by length.
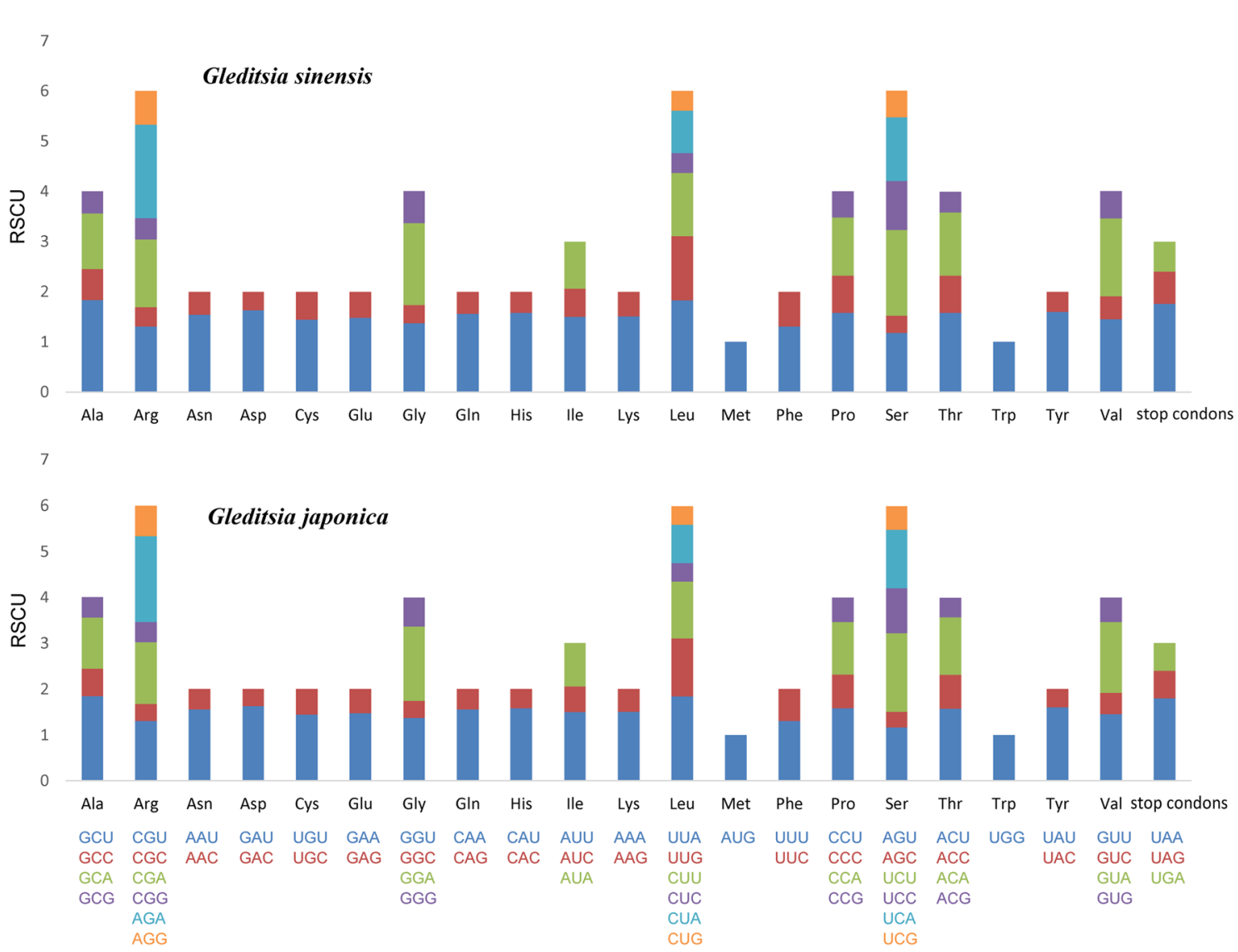

Figure 3. Codon contents of the 20 amino acids and stop codons in all protein-coding genes in the chloroplast genomes of the two Gleditsia species. 


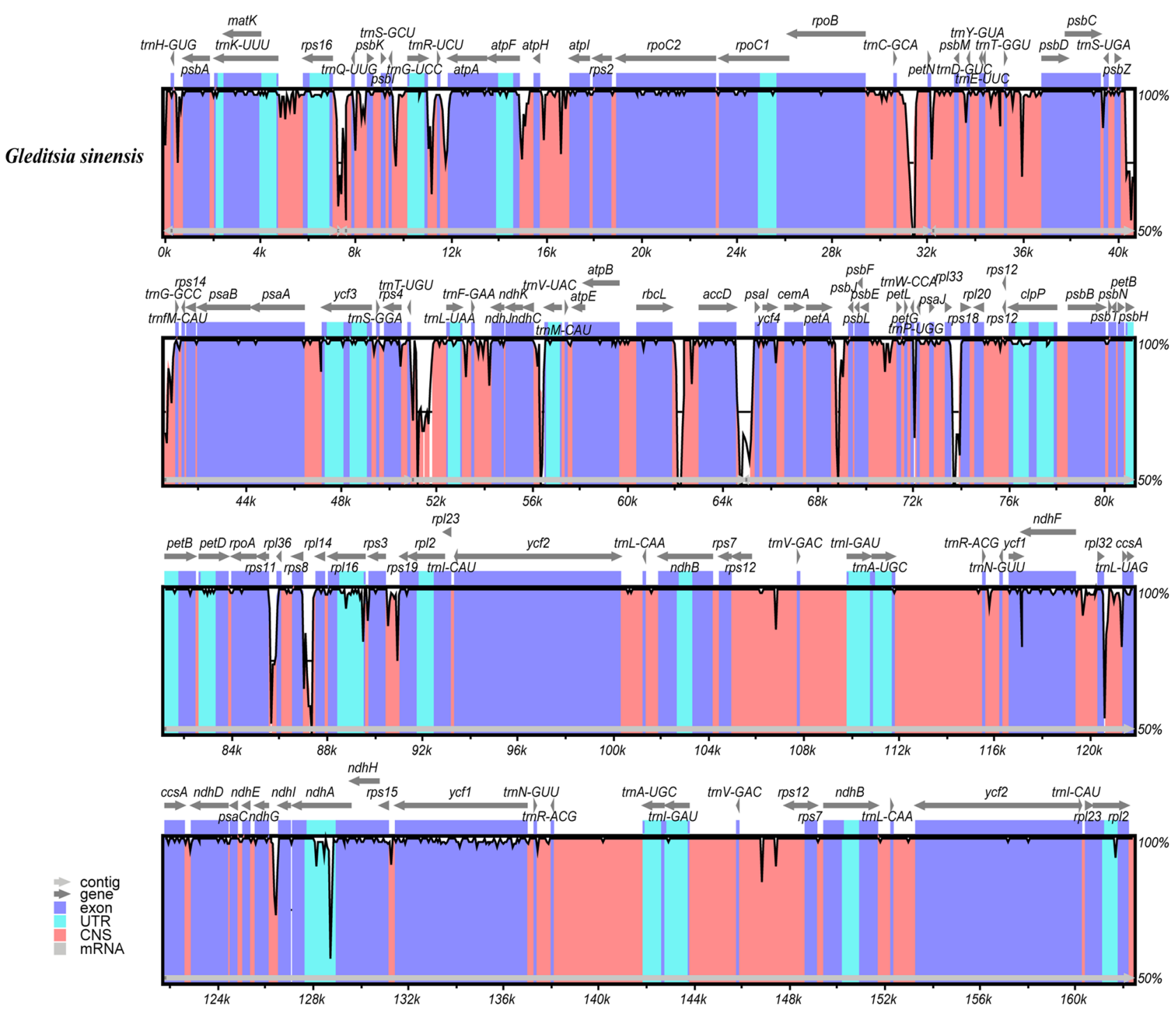

Figure 4. Visual alignment of the chloroplast genomes of the two Gleditsia species. VISTA-based identity plot showing sequence identity among the two species, using G. japonica as reference.

Phylogenetic analysis. Recent advances in high-throughput sequencing provide large amounts of data, which could improve phylogenetic resolution ${ }^{41,46}$. Furthermore, chloroplast genomes have proven highly reliable in inferring the phylogenetic relationships between numerous plant groups ${ }^{47}$. In this study, phylogenetic relationships in the Leguminosae family were reconstructed based on 75 protein-coding genes from 155 legume species. The phylogenetic tree was divided into six subfamilies, which accorded well with the Fabaceae classification system revised in $2017^{48}$ (Fig. 5), all the nodes were moderately or highly supported. In our study, three species of the Gleditsia genus formed a monophyletic clade with strong bootstrap values. The phylogenetic position of Gleditsia is consistent with previous study reports ${ }^{22,48-50}$. Our data will be a useful resource for molecular phylogeny studies within Leguminosae, particularly regarding the role of G. sinensis and G. japonica in plant systematics and evolution.

Analysis of sequence divergences and DNA mini-barcodes. Highly variable DNA regions of chloroplast genomes could be used to distinguish between closely related species ${ }^{51}$. In this study, a total of 130 genes shared between the two Gleditsia species were used to estimate nucleotide diversity. The results showed that nucleotide variability ( $\mathrm{Pi}$ ) of the two species ranged from 0.00001 to 0.02333 (Fig. 6), with a mean of 0.00210 . Meanwhile, the SSC region showed the highest levels of divergence. In this region, $y c f 1 \mathrm{~b}$ exhibited remarkably higher Pi values (0.02333), and was, thus, treated as a potential marker for distinguishing between these two species. Two primer pairs were designed within $y c f 1$ b using Primer $3^{52}$ (Table 3), and amplicons from the two Gleditsia species were compared with other plant universal marker regions of $r b c L^{53}$, and $n d h F, r p l 16^{21}$, trnL-trnF, trnL intron $^{22}, p s b A$-trn $H^{23}$ and $m a t K^{24}$ as described in previous studies. As Table 4 indicates, two short regions of $y c f 1 \mathrm{~b}$ (189 bp and $134 \mathrm{bp}$, respectively) had more variable sites. This result is consistent with the previous report 
A

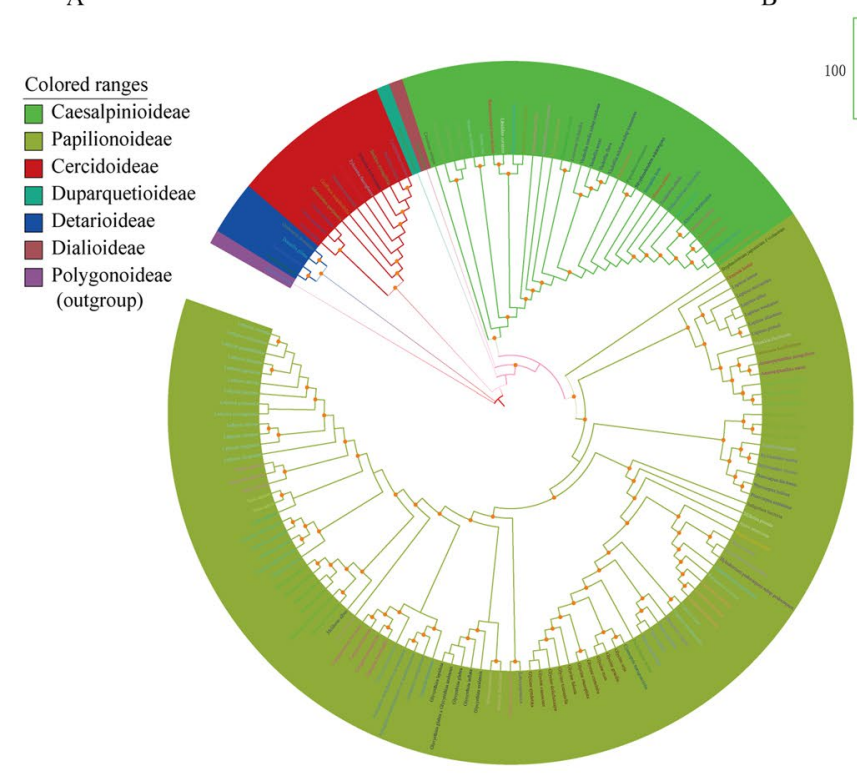

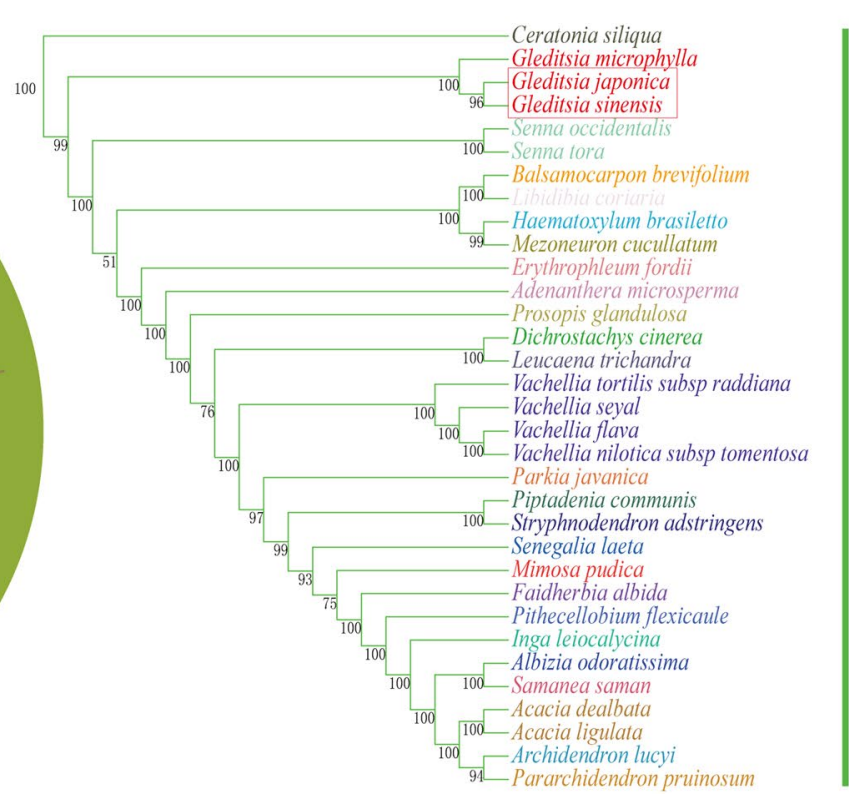

Figure 5. Phylogenetic tree reconstruction of the 155 species inferred from maximum likelihood (ML) based on 75 protein-coding genes of the complete chloroplast genomes. (A) Phylogenetic relationship of Leguminosae, the orange dots at nodes on the tree indicate bootstrap values $(=100)$. (B) Phylogenetic relationship of Caesalpiniaceae, numbers at nodes on the tree represent bootstrap values.

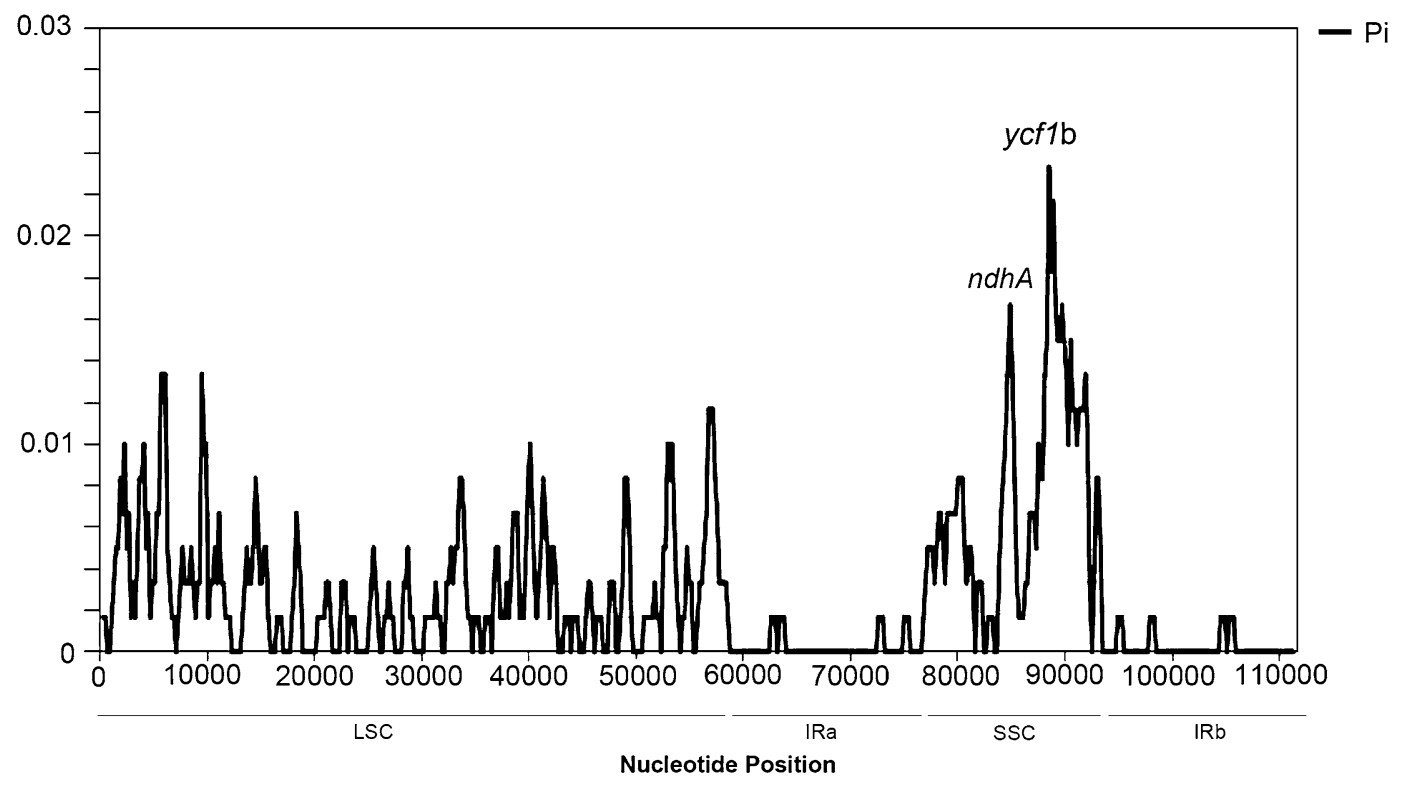

Figure 6. Nucleotide diversity (Pi) based on sliding window analysis of G. sinensis and G. japonica using 130 chloroplast genes. $\mathrm{X}$-axis, the position of the midpoint of a window; Y-axis, nucleotide diversity of each window.

\begin{tabular}{|l|l|l|}
\hline Primer name & ZJ818F-1038R & ZJ1118F-1287R \\
\hline Forward primer sequence $5^{\prime}$ to 3 & CTTCCAAAACGAAGAT & CTAGTTTGTCAACTTTTC \\
\hline Reverse primer sequence $5^{\prime}$ to 3 & AGCATTTTCAAATCGA & AAATTCCTTATCTAGAGC \\
\hline Amplicon size (bp) & 221 & 170 \\
\hline Sequence size excluding primers (bp) & 189 & 134 \\
\hline
\end{tabular}

Table 3. Two pairs of primers of $y c f 1 \mathrm{~b}$ mini-barcodes. 


\begin{tabular}{|c|c|c|c|c|c|c|}
\hline \multirow[b]{2}{*}{ Number } & \multirow[b]{2}{*}{ Marker region } & \multirow[b]{2}{*}{ Aligned length (bp) } & \multicolumn{2}{|c|}{ Variable sites } & \multirow[b]{2}{*}{ K2P } & \multirow[b]{2}{*}{ References } \\
\hline & & & Number & $\%$ & & \\
\hline 1 & $y c f 1 b-Z J 818 \mathrm{~F}-1038 \mathrm{R}$ & 189 & 6 & 3.175 & 0.03260 & This paper \\
\hline 2 & $y c f 1 b-\mathrm{ZJ} 1118 \mathrm{~F}-1287 \mathrm{R}$ & 134 & 6 & 4.478 & 0.04690 & This paper \\
\hline 3 & matK & 1500 & 8 & 0.533 & 0.00536 & Wojciechowski et al \\
\hline 4 & $r b c L$ & 703 & 4 & 0.569 & 0.00571 & Chen et al \\
\hline 5 & $\operatorname{trnH}-p s b A$ & 438 & 5 & 1.142 & 0.01240 & Liu et al \\
\hline 6 & $n d h F$ & 2098 & 11 & 0.524 & 0.00527 & Schnabel et al \\
\hline 7 & rpl16 intron & 1122 & 11 & 0.980 & 0.01040 & Schnabel et al \\
\hline 8 & trnL intron & 566 & 5 & 0.883 & 0.00890 & Herendeen et al \\
\hline 9 & $\operatorname{trnL} L-\operatorname{trn} F$ & 499 & 7 & 1.402 & 0.01440 & Herendeen et al \\
\hline
\end{tabular}

Table 4. Features of nine marker regions in these two Gleditsia species.

that $y c f 1$ is one of the most promising chloroplast DNA barcodes for land plant ${ }^{54}$. In ginsengs (another Chinese medicinal herb), $y c f 1 \mathrm{~b}$ also has $100 \%$ discriminating power for closely related species ${ }^{20}$.

Validation of the quantitative capacity of mini-barcode primers by metabarcoding. The DNA of three artificial mocks consisting of two Gleditsia species was extracted, PCR conducted using the two primer pairs described above, and the respective amplicons were submitted for high-throughput sequencing. The raw data consisted of 1,549,811 reads, of which 1,394,781 high-quality reads were retained after denoising and removal of low-quality and chimeric sequences with DADA2. Subsequently, we generated 3 (product of ZJ818F-1038R) and 5 (product of ZJ1118F-1287R) reliable amplicon sequence variants (ASV) for each amplicon, respectively. In ZJ818F-1038R, all ASVs could be identified as either G. sinensis or G. japonica. For ZJ1118F1287R, 3 ASVs could be identified, accounting for 99.9\% of the total sequences (Supplementary Tables S5-S6). As expected, both primer sets could recover species with very low abundance (1.1\%). The results exhibited that the two species presented positive relationships between biomass and read counts, especially for the mini-barcode of primer ZJ818F-1038R, with significant correlations (Fig. 7). Overall, we expect that this mini-barcode can be used for the quantitative identification of the two Gleditsia species in actual production.

Evaluation of the efficiency of the mini-barcode of primers ZJ818F-1038R in identifying processed medicinal materials. PCR analysis showed that primer ZJ818F-1038R had an excellent amplification efficiency of processed medicinal herbs and Chinese patent medicine (Supplementary Fig. S2). Sanger sequencing of the amplicons from $\mathrm{Da}$ Zao Jiao, Zao Jiao Ci, and Wang Bi capsules identified all the three samples as G. sinensis, with similarities of $99.47 \%, 100 \%, 100 \%$, respectively (Supplementary Table S7).

\section{Conclusions}

In this study, we assembled and characterized the complete chloroplast genomes of G. sinensis and G. japonica. The basic gene information, RNA editing sites, and codon usage patterns were revealed. A total of 93 and 100 SSR were identified in the complete chloroplast genomes of G. sinensis and G. japonica, respectively. Comparative analysis showed that the two Gleditsia species have similar chloroplast genome structures and showed an overall high degree of synteny. Also, we found that $y c f 1 \mathrm{~b}$ was the most variable region among 130 genes, and could, thus, be treated as a potential DNA mini-barcode marker. Quantitative analysis based on $y c f 1$ markers using the metabarcoding method was conducted, and the result showed that primer ZJ818F-1038R have more accurate quantitative ability. Overall, the findings of our study will shed light on the genetic evolution and species identification of G. sinensis and G. japonica.

\section{Discussion}

With the increased application of high-throughput sequencing technology, the number of characterized chloroplast genomes of angiosperms is increasing rapidly ${ }^{55}$. In this study, we found that the two newly sequenced Gleditsia species have similar quadripartite structure and gene contents to the published chloroplast genomes of other members of the Caesalpinioideae sub-family ${ }^{15,56-58}$. According to phylogenetic analysis results, the genus Gleditsia forms a monophyletic clade with strong bootstrap values, which is consistent with the results of previous studies $^{22,48-50}$. The Caesalpinioideae subfamily belongs to the Fabaceae family, which is divided into three longrecognized subfamilies, Caesalpinioideae, Mimosoideae, and Papilionoideae ${ }^{59}$. However, phylogenetic analysis based on matK $_{\text {genes }}{ }^{48}$, nuclear genes (CYC2 genes) ${ }^{50}$ and chloroplast genomes ${ }^{15,57}$ suggests that the Fabaceae family should be divided into six subfamilies: Duparquetioideae, Cercidoideae, Detarioideae, Dialioideae, Caesalpinioideae, and Papilionoideae, which is now accepted widely. In our study, 155 Fabaceae species were used to construct phylogenetic trees based on chloroplast protein-coding genes. Our result is consistent with the recent phylogenomic analyses of Fabaceae.

Compared to traditional methods, DNA barcoding can be applied to accurately identify G. sinensis and its adulterant, G. japonica. DNA barcodes refer to relatively short fragments of DNA with substantial genetic variation, which can be standardized, easily amplified, and representative ${ }^{55}$. DNA degradation frequently occurs 


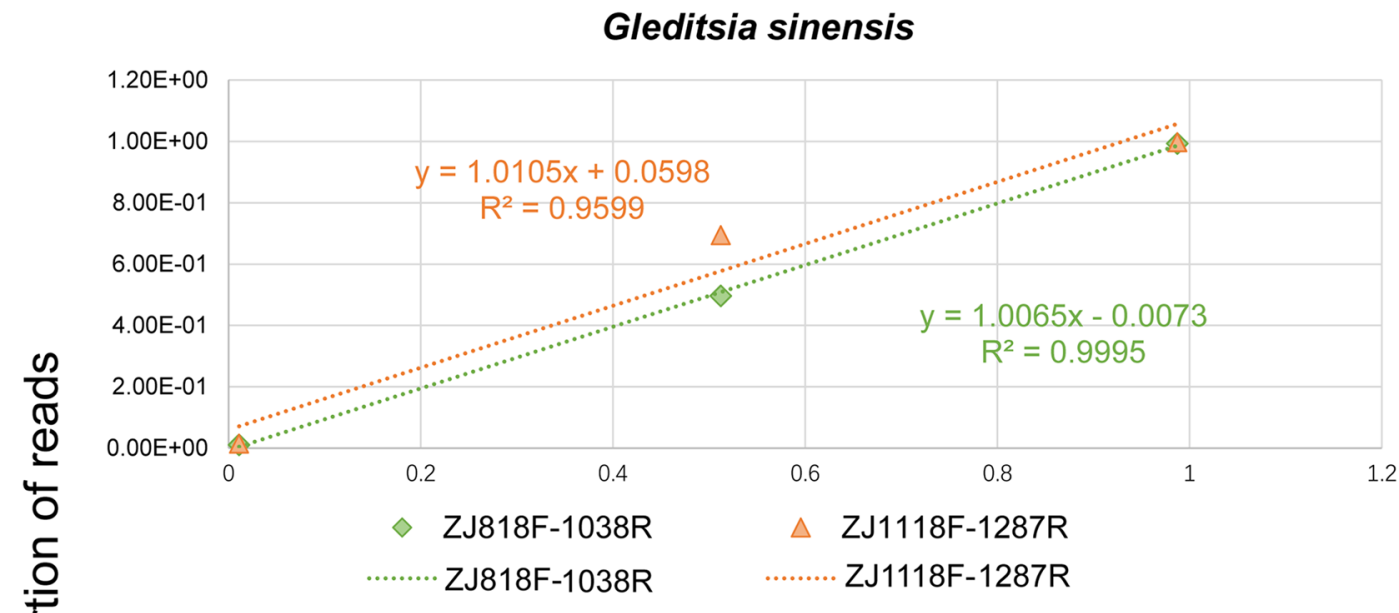

\section{Gleditsia japonica}

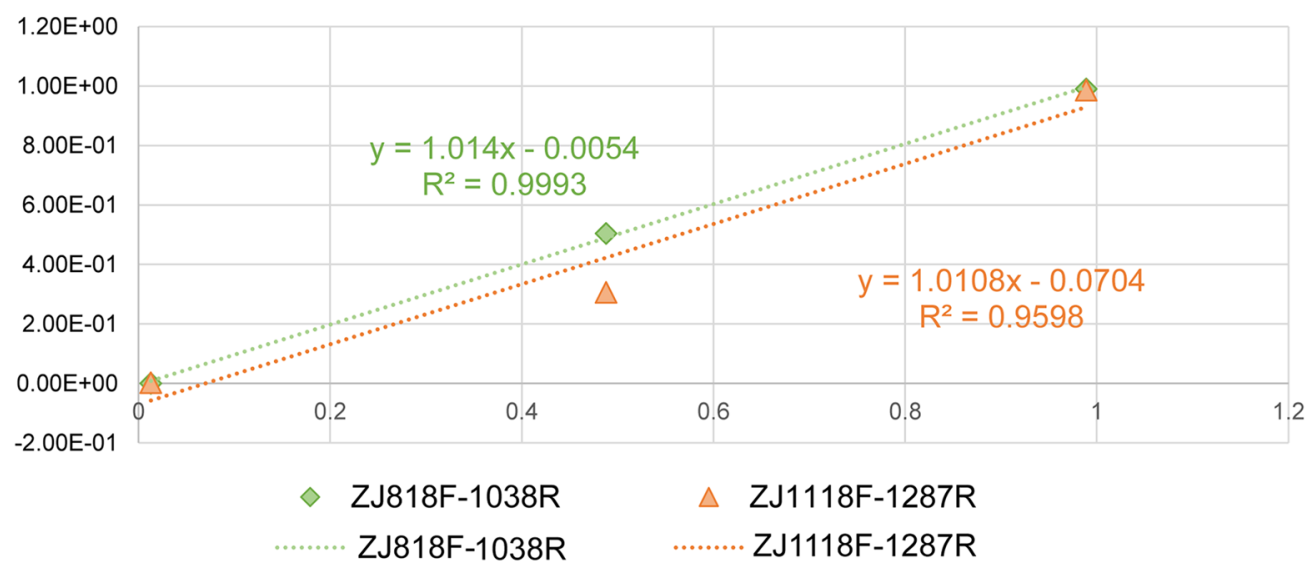

\section{Proportion of biomass}

Figure 7. The relationship between biomass and read counts of the products amplified by the two primer pairs (ZJ818F-1038R and ZJ1118F-1287R) in the two species. X-axis, the proportion of biomass; Y-axis, the proportion of reads.

during the production of natural medicine, which can decrease the efficiency of $\mathrm{PCR}^{29}$. According to the previous studies ${ }^{20,25}$, the usage of short DNA fragments, such as mini-barcodes, can effectively mitigate this problem. Additionally, with the advancement in high-throughput sequencing and metabarcoding, the development of mini-barcode primers is encouraged, which will, in turn, improve the efficiency of taxon discovery and identification $^{60,61}$, especially in mixed samples. In the present study, metabarcoding was performed via sequencing of two mini-barcode amplicons, and quantitative assessments were conducted on three artificial communities. Taberlet et al. ${ }^{62}$ have suggested that the quantitative ability of metabarcoding remains to be tested, due to primer bias. However, the PCR product of primer ZJ818F-1038R used in this study showed highly significant correlations between read counts and biomass, thus good quantitative ability. Subsequently, the mini-barcode of primer ZJ818F-1038R was found useful for identifying processed medicinal materials acquired in markets. Although the universality of our marker has not been sufficiently tested, it can solve our main problem. We believe that this mini-barcode method will guide related quality control research on other herbal medicines and that it will be continually applied in relevant research fields.

\section{Materials and methods}

Plant material preparation and sequencing. Fresh G. sinensis and G. japonica plants were picked from the garden of Tianjin University of Traditional Chinese Medicine, Tianjin, China. The voucher samples were dried and preserved in the Tianjin State Key Laboratory of Modern Chinese Medicine. A Genomic DNA extraction Kit (Sangon Biotech Co., Ltd., Shanghai, China) was used to extract the total genomic DNA. DNA purity and quantity were evaluated using a NanoPhotometer spectrophotometer (IMPLEN, CA, USA) and a Qubit 2.0 Fluorometer (Life Technologies, CA, USA), respectively. The sequencing library was generated by a Truseq Nano DNA HT Sample Preparation Kit (Illumina USA) following the manufacturer's recommendations. The library was sequenced on Illumina HiSeq X Ten platform, and $150 \mathrm{bp}$ paired-end reads were generated. 
Complete chloroplast genome construction and annotation. The total clean reads (G. sinensis and G. japonica) were filtered and assembled into contigs using GetOrganelle pipeline ${ }^{63}$. After that, the clean reads were re-mapped to the complete draft chloroplast genome to confirm each base, respectively. We used different tools such as DOGMA ${ }^{64}$, CPGAVAS2 $2^{65}$, and $\mathrm{GeSeq}^{66}$ to annotate genes of the chloroplast genome. tRNAscan$\mathrm{SE}^{67}$ was employed to verify the tRNA genes. All genes were inspected carefully against the published complete chloroplast genomes of Caesalpiniaceae (KU569489, MF741770, NC_026134, NC_028732, NC_028733, NC_034986, NC_034987, NC_034988, NC_034989, NC_034990, NC_034991, NC_034992, NC_035346, NC_035347, and NC_035348). All the start and stop codons were adjusted manually. Subsequently, the physical maps of the two complete chloroplast genome sequences were visualized with OrganellarGenomeDRAW ${ }^{68}$. The annotated genome sequences of G. sinensis and G. japonica were submitted to the GenBank (accession numbers: MK817503, MK817502).

Repeated sequences and microsatellites. $\mathrm{MISA}^{69}$ was employed to predict single sequence repeats (SSR) or microsatellites in the complete chloroplast genome of the two Gleditsia species. The minimum number of repeats was set to $10,6,5,5,5$, and 5 for mononucleotide, dinucleotide, trinucleotide, tetranucleotide, pentanucleotide, and hexanucleotide, respectively. We also identified forward (F), reverse (R), complementary $(\mathrm{C})$, and palindromic $(\mathrm{P})$ repeats using the online REPuter software ${ }^{70}$, with a minimum repeat size of $30 \mathrm{bp}$ and a Hamming distance of 3 . Tandem repeats were detected by Tandem Repeats Finder web tool ${ }^{71}$, using default parameters.

Analysis and comparison of genome structures. Codon usage was determined by MEGA- $\mathrm{X}^{72} .35$ protein-coding genes of G. sinensis and G. japonica chloroplast genomes were used to predict the potential RNA editing sites by the online program Predictive RNA Editor for Plants suite ${ }^{73}$, using default parameters. The program mVISTA $^{74}$ in Shuffle-LAGAN mode was used to perform the structural comparison of two chloroplast genomes. At the same time, structural variations between the two Gleditsia chloroplast genomes were further compared by the Mauve software ${ }^{75}$.

Phylogenetic analysis. Phylogenetic analysis was based on 75 shared protein-coding genes of the chloroplast genomes of 155 members of the Leguminosae family, including G. sinensis and G. japonica. Rumex acetosa (Polygonaceae) was used as an outgroup (Supplementary Table S8). Alignments were performed by MAFFT v7 with default parameters ${ }^{76}$. A maximum likelihood (ML) approach was used to infer phylogenetic relationships. Maximum likelihood analysis was performed using IQ-TREE v1.6.17, with 1,000 bootstrap replicates. The bestfit model was determined by ModelFinder ${ }^{78}$.

Analysis of sequence divergences. To analyze nucleotide diversity, we performed a sliding window analysis to assess nucleotide variability $(\mathrm{Pi})$ by the DnaSP software version $6.11 .01^{79}$. The window length was set to $600 \mathrm{bp}$, and the step size was $200 \mathrm{bp}$.

Validation of the quantitative capacity of mini-barcode primers by metabarcoding. To verify the quantitative ability of these two primer pairs in our subjects, three mock communities were prepared, containing G. sinensis and G. japonica (Supplementary Table S9). Genomic DNA was extracted from each mock community, respectively. The target regions were amplified using two pairs of fusion primers with matching tags (e.g., F1-R1, F2-R2.) (Supplementary Table S10) to ensure that tag jumps would not result in the false assignment of sequences to samples ${ }^{80}$. PCR amplification was conducted in a $25 \mu \mathrm{l}$ reaction composed of $12.5 \mu \mathrm{l}$ of TaKaRa $2 \times$ Gflex PCR Buffer (containing $1 \mathrm{mM}$ of $\mathrm{Mg}^{2+}$ and $200 \mu \mathrm{M}$ of each dNTP), $0.2 \mu \mathrm{M}$ of each primer, $0.5 \mu \mathrm{l} \mathrm{Tks}$

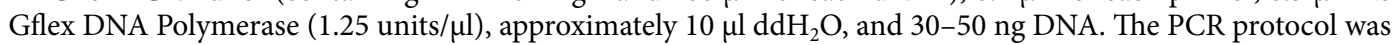
as follows: preheating at $94{ }^{\circ} \mathrm{C}$ for $1 \mathrm{~min}, 30$ cycles at $98^{\circ} \mathrm{C}$ for $10 \mathrm{~s}$, annealing at $55^{\circ} \mathrm{C}$ for $15 \mathrm{~s}$, and elongation at $68{ }^{\circ} \mathrm{C}$ for $30 \mathrm{~s}$, followed by a final extension at $68^{\circ} \mathrm{C}$ for $5 \mathrm{~min}$. Negative controls were included in each run. Amplicons (including negative controls) were resolved on 1.5\% agarose gels and sequenced $(2 \times 150$ bp pairedends) on the Illumina Hiseq X Ten platform.

The fastq-mult ${ }^{81,82}$ was used to split data according to the tag sequences. Primer sequences were trimmed by BBDuk (https://sourceforge.net/projects/bbmap/). To construct ASV, denoise, and quality control (including removal of chimeras) were performed with the DADA $2^{83}$. Meanwhile, reads were truncated to exclude low-quality data (N120 bp for forward reads and N120 bp for reverse reads, truncQ =2, maxEE $=2$ ). In addition, taxonomy was assigned to ASV with the chloroplast genome in our work ( $99 \%$ similarity at least). The relationship between biomass and individual reads was visualized for each species.

Evaluation of the efficiency of the mini-barcode of primers ZJ818F-1038R in identifying processed medicinal materials. Two samples from different parts of G. sinensis, named Da Zao Jiao (fruit), Zao Jiao Ci (thorn), and one type of Chinese patent medicine (Wang Bi capsules), were purchased from the market to test the amplification ability of primers ZJ818F-1038R. PCR method was similar to the part of "Validation the quantitative capacity of mini-barcode primers by metabarcoding". PCR products were sequenced by the Sanger method. 
Received: 17 December 2019; Accepted: 7 September 2020

Published online: 01 October 2020

\section{References}

1. Zhang, J. P. et al. Gleditsia species: an ethnomedical, phytochemical and pharmacological review. J. Ethnopharmacol. 178, 155-171. https://doi.org/10.1016/j.jep.2015.11.044 (2016).

2. Guo, Q. \& Ricklefs, R. E. Species richness in plant genera disjunct between temperate eastern Asia and North America. Bot. J. Linn. Soc. 134, 401-423. https://doi.org/10.1006/bojl.2000.0345 (2000).

3. Zhang, H., Zhang, Y., Wang, Y., Zhan, R. \& Chen, Y. A new neolignan from the thorns of Gleditsia japonica var. delavayi. Nat. Prod. Res. 33, 239-243. https://doi.org/10.1080/14786419.2018.1443101 (2019).

4. Jiangsu New Medical College, b. Dictionary Traditional Drugs (Shanghai Science \& Technology Press, Shanghai) 1431.

5. Chinese Pharmacopoeia Commission, a. The Pharmacopoeia of the People's Republic of China 21 (China Medical Science Press, Beijing, China, 2015).

6. Chinese Pharmacopoeia Commission, b. The Pharmacopoeia of the People's Republic of China 177 (China Medical Science Press, Beijing, China, 2015).

7. Lee, S. J. et al. Suppressive effects of an ethanol extract of Gleditsia sinensis thorns on human SNU-5 gastric cancer cells. Oncol. Rep. 29, 1609-1616. https://doi.org/10.3892/or.2013.2271 (2013).

8. Yu, J. et al. Anti-breast cancer triterpenoid saponins from the thorns of Gleditsia sinensis. Nat. Prod. Res. 33, 2308-2313. https:// doi.org/10.1080/14786419.2018.1443092 (2019).

9. Neuhaus, H. E. \& Emes, M. J. Nonphoto synthetic metabolism in plastids. Annu. Rev. Plant Physiol. Plant Mol. Biol. 51, 111-140. https://doi.org/10.1146/annurev.arplant.51.1.111 (2000).

10. Xie, D. F. et al. Comparative analysis of the chloroplast genomes of the Chinese endemic genus and their contribution to chloroplast phylogeny and adaptive evolution. Int. J. Mol. Sci. https://doi.org/10.3390/ijms19071847 (2018).

11. Wang, W. et al. The Spirodela polyrhiza genome reveals insights into its neotenous reduction fast growth and aquatic lifestyle. Nat. Commun. 5, 3311. https://doi.org/10.1038/ncomms4311 (2014)

12. Hansen, D. R. et al. Phylogenetic and evolutionary implications of complete chloroplast genome sequences of four early-diverging angiosperms: Buxus (Buxaceae), Chloranthus (Chloranthaceae), Dioscorea (Dioscoreaceae), and Illicium (Schisandraceae). Mol. phylogenet. Evol. 45, 547-563. https://doi.org/10.1016/j.ympev.2007.06.004 (2007).

13. Shaw, J. et al. The tortoise and the hare II: relative utility of 21 noncoding chloroplast DNA sequences for phylogenetic analysis. Am. J. Bot. 92, 142-166. https://doi.org/10.3732/ajb.92.1.142 (2005).

14. Yang, Z. et al. The complete chloroplast genomes of three Betulaceae species: implications for molecular phylogeny and historical biogeography. PeerJ 7, e6320. https://doi.org/10.7717/peerj.6320 (2019).

15. Zhang, R. et al. Exploration of plastid phylogenomic conflict yields new insights into the deep relationships of Leguminosae. Syst. Biol. https://doi.org/10.1093/sysbio/syaa013 (2020).

16. Zhao Jing, W. S., \& Ling J. Pharmacognostic identification of Thorns of Gleditsia sinensis with Gleditsia japonica. Asia Pacific Tradit. Med.8 (2012).

17. Li, J. et al. HPLC-MS/MS determination of flavonoids in Gleditsiae Spina for its quality assessment. J. Sep. Sci. 41, $1752-1763$. https://doi.org/10.1002/jssc.201701249 (2018).

18. Zhou, Y., Nie, J., Xiao, L., Hu, Z. \& Wang, B. Comparative chloroplast genome analysis of rhubarb botanical origins and the development of specific identification markers. Molecules https://doi.org/10.3390/molecules23112811 (2018).

19. Chen, S. et al. A renaissance in herbal medicine identification: from morphology to DNA. Biotechnol. Adv. 32, 1237-1244. https ://doi.org/10.1016/j.biotechadv.2014.07.004 (2014).

20. Dong, W. et al. A chloroplast genomic strategy for designing taxon specific DNA mini-barcodes: a case study on ginsengs. BMC Genet. 15, 138. https://doi.org/10.1186/s12863-014-0138-z (2014).

21. Schnabel, A. \& Wendel, J. F. Cladistic biogeography of Gleditsia (Leguminosae) based on ndhF and rpl16 chloroplast gene sequences. Am. J. Bot. 85, 1753-1765 (1998).

22. Herendeen, P., Lewis, G. \& Bruneau, A. Floral morphology in caesalpinioid legumes: testing the monophyly of the "Umtiza Clade". Int. J. Plant Sci. https://doi.org/10.1086/376881 (2003).

23. Liu, J. et al. BOKP: A DNA barcode reference library for monitoring herbal drugs in the Korean pharmacopeia. Front. Pharmacol. 8, 931. https://doi.org/10.3389/fphar.2017.00931 (2017).

24. Wojciechowski, M. F., Lavin, M. \& Sanderson, M. J. A phylogeny of legumes (Leguminosae) based on analysis of the plastid matK gene resolves many well-supported subclades within the family. Am. J. Bot. 91, 1846-1862. https://doi.org/10.3732/ajb.91.11.1846 (2004)

25. Little, D. P. A DNA mini-barcode for land plants. Mol. Ecol. Resour. 14, 437-446. https://doi.org/10.1111/1755-0998.12194 (2014).

26. Gao, Y.-Z., Wei, J., Liu, Z.-W. \& Zhou, J. Application of DNA metabarcoding technology in identification of Chinese patent medicines. China J. Chin. Mater. Med. 44, 261-264. https://doi.org/10.19540/j.cnki.cjcmm.20181106.006 (2019).

27. Meusnier, I. et al. A universal DNA mini-barcode for biodiversity analysis. BMC Genom. 9, 214. https://doi.org/10.1186/14712164-9-214 (2008)

28. Srirama, R. et al. Are mini DNA-barcodes sufficiently informative to resolve species identities? An in silico analysis using Phyllanthus. J. Genet. 93, 823-829. https://doi.org/10.1007/s12041-014-0432-6 (2014).

29. Gao, Z., Liu, Y., Wang, X., Wei, X. \& Han, J. DNA mini-barcoding: a derived barcoding method for herbal molecular identification. Front. Plant Sci. 10, 987. https://doi.org/10.3389/fpls.2019.00987 (2019).

30. Dong, W., Xu, C., Cheng, T., Lin, K. \& Zhou, S. Sequencing angiosperm plastid genomes made easy: a complete set of universal primers and a case study on the phylogeny of saxifragales. Genome Biol. Evol. 5, 989-997. https://doi.org/10.1093/gbe/evt063 (2013).

31. Doyle, J. J., Doyle, J. L. \& Palmer, J. D. Multiple independent losses of two genes and one intron from legume chloroplast genomes. Syst. Bot. 20, 272-294. https://doi.org/10.2307/2419496 (1995).

32. Gantt, J. S., Baldauf, S. L., Calie, P. J., Weeden, N. F. \& Palmer, J. D. Transfer of rpl22 to the nucleus greatly preceded its loss from the chloroplast and involved the gain of an intron. EMBO J. 10, 3073-3078 (1991).

33. Wang, Y.-H., Qu, X.-J., Chen, S.-Y., Li, D.-Z. \& Yi, T.-S. Plastomes of Mimosoideae: structural and size variation, sequence divergence, and phylogenetic implication. Tree Genet Genomes 13, 1. https://doi.org/10.1007/s11295-017-1124-1 (2017).

34. Jansen, R. K., Wojciechowski, M. F., Sanniyasi, E., Lee, S. B. \& Daniell, H. Complete plastid genome sequence of the chickpea (Cicer arietinum) and the phylogenetic distribution of rps 12 and clpP intron losses among legumes (Leguminosae). Mol. Phylogenet. Evol. 48, 1204-1217. https://doi.org/10.1016/j.ympev.2008.06.013 (2008)

35. Xu, C. et al. Comparative analysis of six Lagerstroemia complete chloroplast genomes. Front. Plant Sci. 8, 15. https://doi.org/10.3389/ fpls.2017.00015 (2017).

36. Leigh, F. J. et al. Using diversity of the chloroplast genome to examine evolutionary history of wheat species. Genet. Resour. Crop Evol. 60, 1831-1842. https://doi.org/10.1007/s10722-013-9957-4 (2013).

37. Liang, T. et al. Genetic diversity of Ziziphus mauritiana germplasm based on SSR markers and ploidy level estimation. Planta https ://doi.org/10.1007/s00425-019-03133-2 (2019). 
38. Kuang, D. Y. et al. Complete chloroplast genome sequence of Magnolia kwangsiensis (Magnoliaceae): implication for DNA barcoding and population genetics. Genome 54, 663-673. https://doi.org/10.1139/g11-026 (2011).

39. Cavalier-Smith, T. Chloroplast evolution: secondary symbiogenesis and multiple losses. Curr. Biol. CB 12, R62-64. https://doi. org/10.1016/s0960-9822(01)00675-3 (2002).

40. Li, B., Lin, F., Huang, P., Guo, W. \& Zheng, Y. Complete chloroplast genome sequence of Decaisnea insignis: genome organization, genomic resources and comparative analysis. Sci. Rep. 7, 10073. https://doi.org/10.1038/s41598-017-10409-8 (2017).

41. Zhou, J. et al. Complete chloroplast genomes of Papaver rhoeas and Papaver orientale: molecular structures, comparative analysis, and phylogenetic analysis. Molecules https://doi.org/10.3390/molecules23020437 (2018).

42. Wang, M. et al. Comparative analysis of asteraceae chloroplast genomes: structural organization, RNA editing and evolution. Plant Mol. Biol. Rep. 33, 1526-1538. https://doi.org/10.1007/s11105-015-0853-2 (2015).

43. Luo, J. et al. Comparative chloroplast genomes of photosynthetic orchids: insights into evolution of the Orchidaceae and development of molecular markers for phylogenetic applications. PLoS ONE 9, e99016. https://doi.org/10.1371/journal.pone.0099016 (2014).

44. Li, X. et al. Comparison of four complete chloroplast genomes of medicinal and ornamental Meconopsis species: genome organization and species discrimination. Sci. Rep. 9, 10567. https://doi.org/10.1038/s41598-019-47008-8 (2019).

45. Chen, H., Deng, L., Jiang, Y., Lu, P. \& Yu, J. RNA editing sites exist in protein-coding genes in the chloroplast genome of Cycas taitungensis. J. Integr. Plant Biol. 53, 961-970. https://doi.org/10.1111/j.1744-7909.2011.01082.x (2011).

46. Yu, X. et al. Complete chloroplast genomes of Ampelopsis humulifolia and Ampelopsis japonica: molecular structure, comparative analysis, and phylogenetic analysis. Plants (Basel, Switzerland) https://doi.org/10.3390/plants8100410 (2019).

47. Chen, Y., Hu, N. \& Wu, H. Analyzing and characterizing the chloroplast genome of Salix wilsonii. BioMed. Res. Int. 2019, 5190425. https://doi.org/10.1155/2019/5190425 (2019).

48. Azani, N. et al. A new subfamily classification of the Leguminosae based on a taxonomically comprehensive phylogeny. Taxon 66, 44-77. https://doi.org/10.12705/661.3 (2017).

49. Manzanilla, V. \& Bruneau, A. Phylogeny reconstruction in the Caesalpinieae grade (Leguminosae) based on duplicated copies of the sucrose synthase gene and plastid markers. Mol. Phylogenet. Evol. 65, 149-162. https://doi.org/10.1016/j.ympev.2012.05.035 (2012).

50. Zhao, Z. et al. Evolution of CYCLOIDEA-like genes in fabales: insights into duplication patterns and the control of floral symmetry. Mol. Phylogenet. Evol. 132, 81-89. https://doi.org/10.1016/j.ympev.2018.11.007 (2019).

51. Jiao, L., Lu, Y., He, T., Li, J. \& Yin, Y. A strategy for developing high-resolution DNA barcodes for species discrimination of wood specimens using the complete chloroplast genome of three Pterocarpus species. Planta 250, 95-104. https://doi.org/10.1007/s0042 5-019-03150-1 (2019).

52. Koressaar, T. \& Remm, M. Enhancements and modifications of primer design program Primer3. Bioinformatics 23, $1289-1291$. https://doi.org/10.1093/bioinformatics/btm091 (2007).

53. Chen, S. et al. Validation of the ITS2 region as a novel DNA barcode for identifying medicinal plant species. PLoS ONE $\mathbf{5}$, e8613. https://doi.org/10.1371/journal.pone.0008613 (2010).

54. Dong, W., Liu, J., Yu, J., Wang, L. \& Zhou, S. Highly variable chloroplast markers for evaluating plant phylogeny at low taxonomic levels and for DNA barcoding. PLoS ONE 7, e35071. https://doi.org/10.1371/journal.pone.0035071 (2012).

55. Ge, Y. et al. Evolutionary analysis of six chloroplast genomes from three Persea americana ecological races: Insights into sequence divergences and phylogenetic relationships. PLoS ONE 14, e0221827. https://doi.org/10.1371/journal.pone.0221827 (2019).

56. Dugas, D. V. et al. Mimosoid legume plastome evolution: IR expansion, tandem repeat expansions, and accelerated rate of evolution in clpP. Sci. Rep. 5, 16958. https://doi.org/10.1038/srep16958 (2015).

57. Koenen, E. J. M. et al. Large-scale genomic sequence data resolve the deepest divergences in the legume phylogeny and support a near-simultaneous evolutionary origin of all six subfamilies. New Phytol. 225, 1355-1369. https://doi.org/10.1111/nph.16290 (2020).

58. Wang, Y.-H., Qu, X.-J., Chen, S.-Y., Li, D.-Z. \& Yi, T. Plastomes of Mimosoideae: structural and size variation, sequence divergence, and phylogenetic implication. Tree Genet. Genomes https://doi.org/10.1007/s11295-017-1124-1 (2017).

59. Käss, E. \& Wink, M. Molecular evolution of the leguminosae: phylogeny of the three subfamilies based on $r b c L$-sequences. Biochem. Syst. Ecol. 24, 365-378. https://doi.org/10.1016/0305-1978(96)00032-4 (1996).

60. Leray, M. et al. A new versatile primer set targeting a short fragment of the mitochondrial COI region for metabarcoding metazoan diversity: application for characterizing coral reef fish gut contents. Front. Zool. 10, 34. https://doi.org/10.1186/1742-9994-10-34 (2013).

61. Govender, A., Groeneveld, J., Singh, S. \& Willows-Munro, S. The design and testing of mini-barcode markers in marine lobsters. PLOS ONE 14, e0210492. https://doi.org/10.1371/journal.pone.0210492 (2019).

62. Bista, I. et al. Performance of amplicon and shotgun sequencing for accurate biomass estimation in invertebrate community samples. Mol. Ecol. Resour. https://doi.org/10.1111/1755-0998.12888 (2018).

63. Jin, J.-J. et al. GetOrganelle: a simple and fast pipeline for de novo assembly of a complete circular chloroplast genome using genome skimming data. bioRxiv https://doi.org/10.1101/256479 (2018).

64. Boore, J. L., Jansen, R. K. \& Wyman, S. K. Automatic annotation of organellar genomes with DOGMA. Bioinformatics 20, 32523255. https://doi.org/10.1093/bioinformatics/bth352 (2004).

65. Shi, L. et al. CPGAVAS2, an integrated plastome sequence annotator and analyzer. Nucleic Acids Res. 47, W65-w73. https://doi. org/10.1093/nar/gkz345 (2019).

66. Tillich, M. et al. GeSeq-versatile and accurate annotation of organelle genomes. Nucleic Acids Res. 45, W6-W11. https://doi. org/10.1093/nar/gkx391 (2017).

67. Lowe, T. M. \& Eddy, S. R. tRNAscan-SE: a program for improved detection of transfer RNA genes in genomic sequence. Nucleic Acids Res. 25, 955-964. https://doi.org/10.1093/nar/25.5.955 (1997).

68. Greiner, S., Lehwark, P. \& Bock, R. OrganellarGenomeDRAW (OGDRAW) version 1.3.1: expanded toolkit for the graphical visualization of organellar genomes. Nucleic Acids Res. https://doi.org/10.1093/nar/gkz238 (2019).

69. Thiel, T., Michalek, W., Varshney, R. K. \& Graner, A. Exploiting EST databases for the development and characterization of genederived SSR-markers in barley (Hordeum vulgare L.). Theor. Appl. Genet. 106, 411-422. https://doi.org/10.1007/s00122-002-1031-0 (2003).

70. Kurtz, S. et al. REPuter: the manifold applications of repeat analysis on a genomic scale. Nucleic Acids Res. 29, 4633-4642 (2001).

71. Benson, G. Tandem repeats finder: a program to analyze DNA sequences. Nucleic Acids Res. 27, 573-580. https://doi.org/10.1093/ nar/27.2.573 (1999).

72. Kumar, S., Stecher, G., Li, M., Knyaz, C. \& Tamura, K. MEGA X: molecular evolutionary genetics analysis across computing platforms. Mol. Biol. Evol. 35, 1547-1549. https://doi.org/10.1093/molbev/msy096 (2018).

73. Mower, J. P. The PREP suite: predictive RNA editors for plant mitochondrial genes, chloroplast genes and user-defined alignments. Nucleic Acids Res. 37, W253-259. https://doi.org/10.1093/nar/gkp337 (2009).

74. Frazer, K. A., Pachter, L., Poliakov, A., Rubin, E. M. \& Dubchak, I. VISTA: computational tools for comparative genomics. Nucleic Acids Res. 32, W273-279. https://doi.org/10.1093/nar/gkh458 (2004).

75. Darling, A. C., Mau, B., Blattner, F. R. \& Perna, N. T. Mauve: multiple alignment of conserved genomic sequence with rearrangements. Genome Res. 14, 1394-1403. https://doi.org/10.1101/gr.2289704 (2004). 
76. Katoh, K. \& Standley, D. M. MAFFT multiple sequence alignment software version 7: improvements in performance and usability. Mol. Biol. Evol. 30, 772-780. https://doi.org/10.1093/molbev/mst010 (2013).

77. Nguyen, L. T., Schmidt, H. A., von Haeseler, A. \& Minh, B. Q. IQ-TREE: a fast and effective stochastic algorithm for estimating maximum-likelihood phylogenies. Mol. Biol. Evol. 32, 268-274. https://doi.org/10.1093/molbev/msu300 (2015).

78. Kalyaanamoorthy, S., Minh, B. Q., Wong, T. K. F., von Haeseler, A. \& Jermiin, L. S. ModelFinder: fast model selection for accurate phylogenetic estimates. Nat. Methods 14, 587-589. https://doi.org/10.1038/nmeth.4285 (2017).

79. Rozas, J. et al. DnaSP 6: dna sequence polymorphism analysis of large data sets. Mol. Biol. Evol. 34, 3299-3302. https://doi. org/10.1093/molbev/msx248 (2017).

80. Schnell, I. B., Bohmann, K. \& Gilbert, M. T. Tag jumps illuminated-reducing sequence-to-sample misidentifications in metabarcoding studies. Mol. Ecol. Resour. 15, 1289-1303. https://doi.org/10.1111/1755-0998.12402 (2015).

81. Aronesty, E. ea-utils : Command-Line Tools for Processing Biological Sequencing Data. https://github.com/ExpressionAnalysis/ ea-utils (2011).

82. Aronesty, E. Comparison of sequencing utility programs. Open Bioinform. J. 7, 1-8. https://doi.org/10.2174/187503620130701 0001 (2013).

83. Callahan, B. J. et al. DADA2: High-resolution sample inference from Illumina amplicon data. Nat. Methods 13, 581-583. https:// doi.org/10.1038/nmeth.3869 (2016).

\section{Acknowledgements}

This work was supported by grants from the National Natural Science Foundation (No. 81803691), Major new drug creation, key technology and variety development of new Chinese medicine drug discovery based on huge data (2019ZX09201005).

\section{Author contributions}

X.-X.T, E.-W.L,W.T and H.G designed the experiment, drafted and revised the manuscript; W.T and H.G analyzed the results. W.-L.J, H.-Y.Z and X.-L.Y prepared plant materials and collected the samples. All authors reviewed the manuscript.

\section{Competing interests}

The authors declare no competing interests.

\section{Additional information}

Supplementary information is available for this paper at https://doi.org/10.1038/s41598-020-73392-7.

Correspondence and requests for materials should be addressed to E.L. or X.T.

Reprints and permissions information is available at www.nature.com/reprints.

Publisher's note Springer Nature remains neutral with regard to jurisdictional claims in published maps and institutional affiliations.

(c) Open Access This article is licensed under a Creative Commons Attribution 4.0 International

License, which permits use, sharing, adaptation, distribution and reproduction in any medium or format, as long as you give appropriate credit to the original author(s) and the source, provide a link to the Creative Commons licence, and indicate if changes were made. The images or other third party material in this article are included in the article's Creative Commons licence, unless indicated otherwise in a credit line to the material. If material is not included in the article's Creative Commons licence and your intended use is not permitted by statutory regulation or exceeds the permitted use, you will need to obtain permission directly from the copyright holder. To view a copy of this licence, visit http://creativecommons.org/licenses/by/4.0/.

(c) The Author(s) 2020 